\title{
ENVIRONMENTAL ASSESSMENT OF NiCd- BATTERY MANUFACTURING -Past and Present Trends
}

\author{
Carl Johan Rydh \\ University of Kalmar, Sweden
}

\begin{abstract}
In order to achieve higher efficiency in use of materials and energy when providing a service or functionality of a product, indicator values can be used to point out the direction of development. The objective of the present study is to assess temporal variations of inventory data and identify significant environmental impacts for a product by using a life cycle assessment (LCA) approach. The study was restricted to a gate-to-gate analysis of a Swedish manufacturer of NiCd batteries during the period 1983-1998. Inputs and outputs of materials and energy were compiled from environmental reports, which were related to the volume of produced batteries. The environmental impact was assessed by evaluation with different characterisation and weighting indices. The characterisation results regarding potential impact in resource use, global warming potential, acidification, eutrophication and aquatic ecotoxicity showed an average decrease of 2- 6 times during the period studied. The results of weighting showed that the environmental impact differed in the range -48 to $91 \%$ per year according to the methods of ECO, ET, EDIP and EPS. The temporal variations of the results show the importance of choosing representative inventory data when making a LCA. Major reasons for the reduction in environmental impact were due to increased production meanwhile reducing dissipative emissions of metals. Evaluation with environmental indices is a great simplification of reality but it can help to identify significant environmental impacts of a product.
\end{abstract}




\section{INTRODUCTION}

To decrease the environmental impact caused by the intense use of materials and energy by the human society, services and functionalities of products have to be provided more efficiently. A factor ten more efficient functionalities of products and services has been proposed as goal for improvements (Schmidt-Bleek 1994). Weizsäcker et al. (1997) showed several encouraging examples from different sectors where improvements of at least a factor four have been achieved, by doing more with less. Several examples of how companies have been working to improve the eco-efficiency of their products are given by Klostermann and Tukker (1998).

Many of the environmental improvements have been possible by providing services in a different way, the use of new technologies and dematerialisation strategies. An increased awareness in society and expanding responsibility of the need to decrease the environmental impact has led to a systematic environmental work and greater investments in resource efficient and environmental technologies.

To achieve higher effectiveness when providing a service, different parameters have to be measured to assess if the development is going in a desirable direction. The standard ISO 14030 (under development) deals with indicators for environmental performance evaluation. Useful indicators for environmental development have to be e.g. relevant, understandable, controllable and reproducible (Kuhre 1998).

Measurable physical indicators for sustainability can be divided into three groups (Holmberg \& Karlsson 1992): (i) activities (flows), (ii) environmental impact (emissions) and (iii) stateof-health indicators (concentrations). Azar et al. (1996) developed socio-ecological principles and indicators focusing on activities, thus making it possible to point out the direction of development early. Nilsson (1997) discussed the application of the principles in firms and proposed indicators suitable for an energy company.

To find relevant indicators all data related to a product have to be evaluated to identify parameters, which contribute significantly to the environmental impact of the product. One method of environmental evaluation is life cycle assessment (LCA), which assesses the potential environmental impact related to a service or functionality provided by a product during its whole life cycle. To make a reliable assessment, data of high quality and relevance have to be compiled. This is not easy to achieve since manufacturing data often is secret of competitive reasons. Data may be obtained from official environmental reports but should preferable be compiled in cooperation with the company involved. The uncertainties of the inventory data and final result of a LCA should be assessed with a sensitivity analysis.

The objective of this study is to assess which influence manufacturing inventory data originating from different years has on the results of a LCA. General trends in environmental impact will be identified and reasons for the changes will be discussed. The relative importance of different parameters will be identified.

A manufacturer of nickel-cadmium (NiCd) batteries was chosen for this study since batteries are important in energy distribution as well as for providing energy for portable electronic products. The handling of hazardous substances and recycling of spent batteries make the company's environmental work especially important. 


\section{MATERIALS AND METHODS}

In this study, the manufacturing of NiCd-batteries at AB SAFT in Oskarshamn, Sweden, was evaluated. The company has 400 employees. The original production of industrial $\mathrm{NiCd}$ batteries dates back to 1915 (Atkinson 1966). The battery construction is based on a patent of pocket plate electrodes of Waldemar Jungner originating from 1899. Since the late 70's, all raw materials are processed in the factory for preparation of the electrodes. A recycling facility for spent industrial batteries is in operation since 1984 and since 1996 also for spent portable batteries.

A life cycle assessment (LCA) approach was used to assess the environmental impact in a gate-to-gate perspective. The phases within this work include compiling an inventory of relevant inputs and outputs related to the functionality of a product (ISO 1997). The environmental impacts associated with the inputs and outputs were evaluated and interpreted to the objectives of the study.

Data of inputs and outputs of the factory were compiled from environmental reports during the period 1983-98, which was completed by interviews with personnel of the company. The inventory data was related to the functionality of the product: the annually produced battery capacity in ampere-hours. Emission values for the production of electricity in Sweden were assumed to be the same during the period studied since the variations are very small. All use of materials and emissions from the factory were allocated to the manufacturing of batteries since the batteries are expected to have long lifetime and it is uncertain how the materials of the spent batteries will be recovered after use.

The impact assessment was made by characterisation (normalisation of emissions contributing to a certain impact category) and weighting (aggregation of inventory results to a single impact value). The characterisation was made with regard to global warming potential, acidification, eutrophication, aquatic ecotoxicity and resource use with the latest indices compiled by CIT (1998). These impact categories were chosen since the available inventory data showed to have a significant effect.

Weighting was done with the quantitative methods of Environmental Theme (ET), eco indicator (ECO 98), Environmental Design of Industrial Products (EDIP) and Environmental Priority Strategies in product design (EPS) (CIT 1998). In the ET method, the different emissions are weighted against political emission goals for various impact categories (e.g. acidification, greenhouse effect). The ECO 98 indices are based on the estimated critical load of different substances of a specified geographic area. The EDIP method is based on the contribution to environmental impact per person and year related to political reduction targets. The EPS method is based on the willingness to pay to restore five safeguarded objects (biodiversity, ecological production, human health, resources and aesthetic values) to their former status without anthropogenic disturbance. Emissions and use of resources are valued to their estimated contribution to changes in the safe guard objects. 


\section{RESULTS}

\section{Inventory}

Swedish legislation demands larger production facilities, classified due to the amount of handled materials, to deliver environmental reports annually to the controlling authorities (in this case to the county administration). The environmental reports have become more detailed the last decade and more specific data have been added e.g. since 1990 all chemicals consumed in the factory have to be reported (SAFT 1983-98). The consumption of different organic solvents has been reduced during the 90's and the use of e.g. trichloro-etylen has ceased completely. Uncertainties about the historical chemical consumption restricted the inventory to parameters given in the environmental reports during the period studied.

The production of batteries has been fairly constant until 1993 when the company increased the production by $60 \%$ due to the replacement of another production site (Fig. 1). In the period 1983-92, the average energy requirements in the manufacturing process, recalculated to primary energy, were 370 times greater than the energy storage capacity in the produced batteries. Since 1993, 60\% larger production has been achieved with a $15 \%$ increase in primary energy input. This has decreased the energy requirements per produced battery to an average of 250 times the battery energy storage capacity.

The non-proportional fluctuations of primary energy during 1984-85 (Fig. 1) are due to variations in the annual investments of liquid petroleum gas (LPG). The net primary energy consumption in the factory during the period studied has increased with an average of $1.6 \%$ per annum. The use of oil has decreased by $10 \%$ while electricity consumption has increased with the corresponding value (recalculated to primary energy). Since 1993, the sulphur content in oil used for heating has been reduced stepwise from $<0.5 \%$ to $<0.1 \%$.

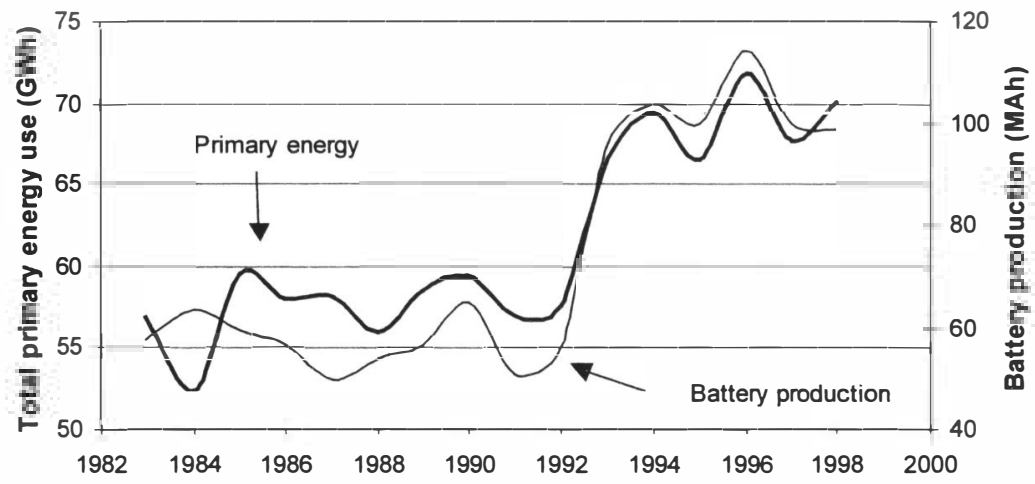

Fig. 1: Primary energy use and production of nickel-cadmium batteries at AB SAFT, Oskarshamn, Sweden, 1983-98 (SAFT 1983-98). 
The volumes of sludge from the waste water treatment plant of the factory, which have to be landfilled, have increased by $62 \%$ in absolute values during the period studied. Related to the produced battery capacity the amounts have been constant.

The registered factory emissions in absolute values of $\mathrm{Cd}$ and $\mathrm{Ni}$ to water have been reduced by an average of $69 \%$ and $91 \%$, respectively, when comparing the average of 1983-1987 and 1994-98. The corresponding values for $\mathrm{Cd}$ and $\mathrm{Ni}$ air emissions showed a reduction of $83 \%$ and $93 \%$, respectively. The environmental control program of the company includes measurements of $\mathrm{Ni}$ and $\mathrm{Cd}$ in the surroundings and the recipient (the harbour of Oskarshamn and the Baltic sea) of the factory. As a consequence of the reduction of emissions, the concentrations of e.g. Cd in bivalves have decreased 1.6- 3 times and $\mathrm{Cd}$ and $\mathrm{Ni}$ in moss 3- 7 times during the last 15 years. The measured concentrations in the surroundings are 3-10 times above natural background concentrations but show a decreasing trend.

\section{Impact assessment}

The emission values of the inventory were multiplied with characterisation indices (CIT 98) to get a value of the impact on each category. Since emissions are related to the functionality of the product. the relative impacts between different years are negatively correlated to the volume of produced batteries, thus causing fluctuations of the graphs (Fig. 2). The results of the impact categories of eutrophication, resource use and acidification showed the same trends as global warming potential (GWP) in Fig. 2. The decrease in environmental impact of the different categories during 1983- 98 was in the range 2- 6 times. The variations between different

Regarding GWP, emissions of $\mathrm{CO}_{2}$ related to energy production contribute with $98 \%$ of the total impact. The reduction in GWP during the period is $60 \%$. Half of the reduction is due to the shift from oil to electricity consumption (Swedish electricity production is based mainly on hydro and nuclear power which have low $\mathrm{CO}_{2}$ emissions). The other half of the reduction is explained by an increased production, which gives a higher utilisation rate of the factory and shares the standing cost per battery produced.

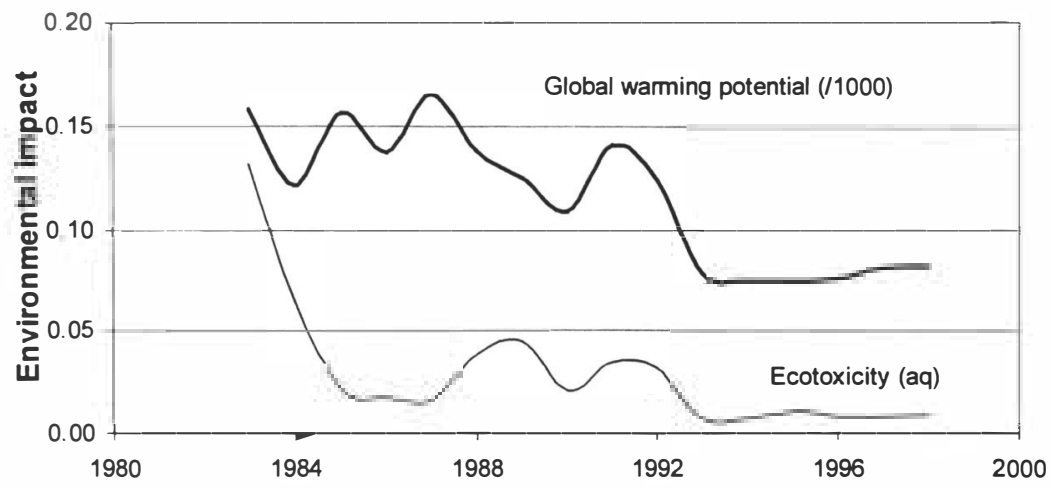

Fig. 2: Relative environmental impact per produced battery on global warming potential and aquatic ecotoxicity of NiCd battery manufacturing during the period 1983-1998. 
Aquatic ecotoxicity is influenced by discharges of e.g. metals and oil into water. Emissions of Cd contribute with $98 \%$ of the total ecotoxiciy. The higher impact in 1983 is due to an occasionally higher emission of $\mathrm{Cd}$ to water. The average reduction in aquatic ecotoxicity during the period is 6 times. The variations between two years following each other are in the range -78 to $+137 \%$. $75 \%$ of the reduction is explained by the decrease in Cd emissions to water while $25 \%$ is due to an increased volume of produced batteries.

The results of weighting with the ET and ECO methods show an average decrease of $4 \%$ per annum during the period (Fig. 3). The variations between two following years are in the range -42 to $33 \%$. The average decrease in environmental impact during the period 1983-86/199598 for the ET and ECO 98 methods is 2 and 3 times respectively.

The most significant contribution to environmental impact of the ET method is the consumption of crude oil. The peaks indicated with 1 in Fig. 3 are due to higher consumption of oil for the company's energy production in combination with a 10-20\% lower production during these years. The consumption of oil per produced battery remained quite constant after 1993 (Number 2 in Fig. 3).

The relative importance of $\mathrm{Cd}$ emissions to air contributed to $90 \%$ of the environmental impact of the ECO method until 1985. Its relative importance decreased to $60 \%$ until 1997 meanwhile the relative importance of oil consumption increased from 4 to $38 \%$. The peaks 1988 and 1991 are mainly due to lower production volumes. After 1993, the impact decreased drastically since the emissions of $\mathrm{Cd}$ to air decreased a factor three meanwhile the production increased.

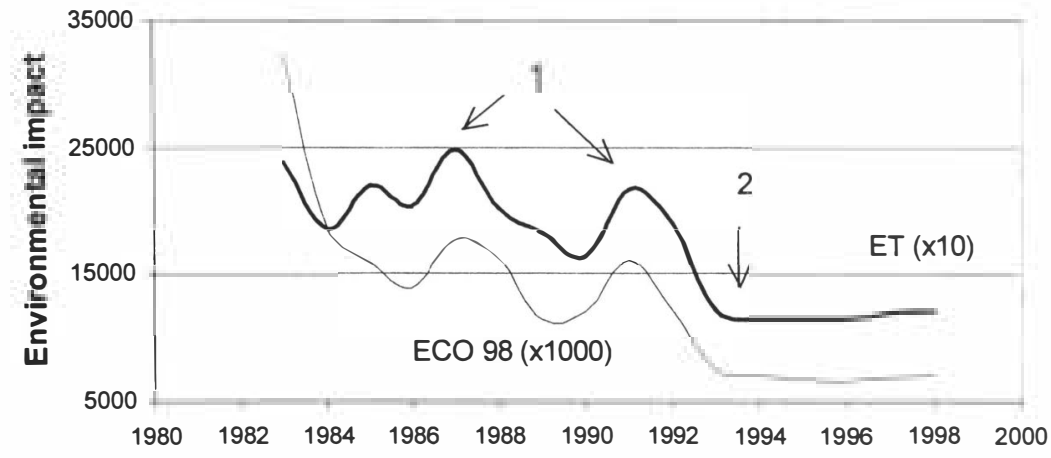

Fig. 3: Relative environmental impact per produced battery during the period 1983-1998 according to the weighting methods of ECO 98 and ET. Numbers are explained in the text. 


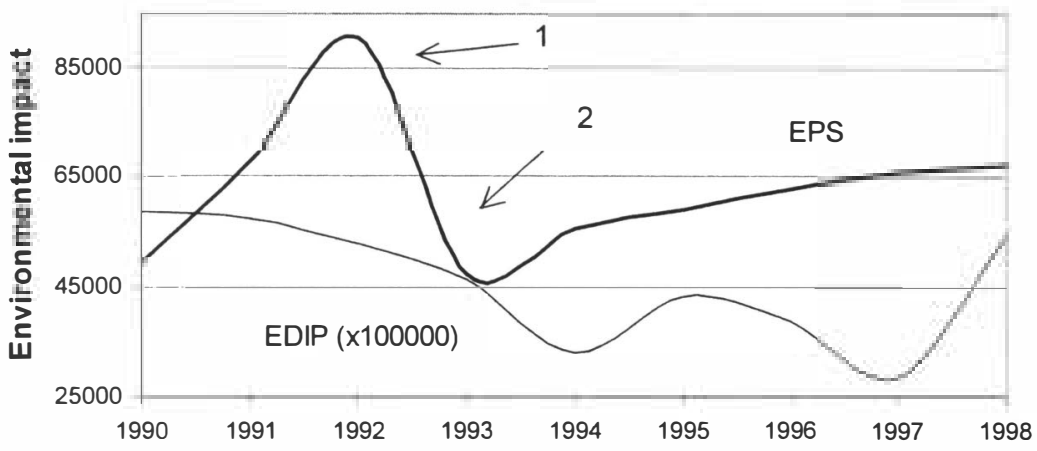

Fig. 4: Relative environmental impact of battery manufacturing during the period 1990-1998 according to the weighting methods of EPS and EDIP. Numbers are explained in the text.

The EPS and EDIP weighting methods have more indices than other methods, which take the use of material resources into consideration. Due to lack of reliable data on metal consumption, weighting with the EPS and EDIP methods could only be calculated for the period 1990-98 (Fig. 4). The consumption of $\mathrm{Ni}$ resources dominates the environmental impact completely for the EDIP method. No EDIP index is available for the use of Cd resources. For the EPS method, the use of $\mathrm{Cd}$ and $\mathrm{Ni}$ resources dominate the environmental impact. The fluctuations of the curves are due to irregularities in supply of raw materials to the factory.

The average environmental impact during 1990-98 decreased by $4 \%$ per annum for the EDIP method while the EPS method showed an increase of $0.7 \%$ per annum. The difference between one year and the following during the period was -29 to $+91 \%$ for the EDIP method and the corresponding result was -48 to $+37 \%$ for the EPS method. The peak ( 1 in Fig. 4$)$ shown by the EPS method is due to $60 \%$ less use of secondary Cd as previous year while the input of primary $\mathrm{Cd}$ is twice as high. In 1993 the impact is $50 \%$ lower than the previous year due to a higher production volume and higher use of recycled Cd (2 in Fig. 4).

\section{DISCUSSION}

The environmental impact of $\mathrm{NiCd}$ battery manufacturing assessed with different characterisation and weighting methods showed a 2- 6 times reduction during the period 198398. The annual variations according to the different weighting methods were in the range -48 to $+91 \%$. These results show the importance of evaluating temporal inventory data when making a complete LCA.

The major reason for the decrease in environmental impact is the increase in production of batteries while emissions have been reduced. This indicates that the factory has a high standing consumption of energy and the production facility can be better utilized. Proactive work of the company and legislative demands has encouraged investments in more efficient 
air and wastewater filtering technologies, which has reduced the losses of Cd and Ni. In 1997 , SAFT contributed with about $90 \%(4.4 \mathrm{~kg})$ and $66 \%(5.5 \mathrm{~kg})$ of the controlled $\mathrm{Cd}$ and $\mathrm{Ni}$ emissions to air of industrial activities in the County of Kalmar respectively (Svensson 1997).

Significant decreased environmental impact can be achieved by increased use of secondary $\mathrm{Ni}$ and $\mathrm{Cd}$ as well as reducing the total energy requirements in the production. In the near future, the factory will eventually be connected to the municipal district heating system. Currently, the municipal boiler is fired by oil and LPG gas. If the taxation of biomass fuels will be more favourable compared to the currently used oil and natural gas (Energiskattegruppen 1999), the municipal boiler will be converted to biomass combustion. If the factory would convert to energy supply from biomass, the fossil carbon dioxide emissions could be reduced by $80 \%$ per produced battery.

There are several examples of environmental actions, which not show to have significant effects even though these actions are of great importance. This problem occurs when a relatively small volume of an element is used or when local effiects are not considered. One example is the ban on the use of trichloro-ethylene (TRI), which use has ceased in Sweden. In 1995, the use of TRI in the factory was totally substituted by isopropyl alcohol. A new process design for degreasing metal bands has now made it possible to stop the use of isopropyl alcohol. Other measurements, which has lead to decreased environmental impact, is the substitution stable chloroflour carbons (CFC R12) used in heat pumps and cooling systems. In 1986, it was replaced with the less stable compound HCFC 134a. Also the emissions of $\mathrm{SO}_{\mathrm{x}}$ have decreased since the sulphur content in oil has been reduced from $0.5 \%$ (until 1993) to less than $0.1 \%$ (1998).

Considering the whole life-cycle of NiCd batteries (Kertes 1996), the major environmental impact is found in the phase of raw materials extraction and refining. Depending on the way of electricity production to charge the batteries, energy efficiency in the user phase is also of significant importance.

The EPS and EDIP methods evaluate the use of resources significantly higher than emissions. This is the reason for the quite constant trend in environmental impact with these methods since metal consumption is proportional to the production of batteries. By using secondary (recycled) metals in batteries, the environmental impact can be reduced since virgin resources are saved. During the 90 's, the produced batteries have been made up by $16-32 \%$ secondary $\mathrm{Cd}$. The factory's Cd recovery from recycling of spent batteries is fully utilised today. Low Cd prices make it less commercial interesting to recycle spent $\mathrm{NiCd}$ batteries. $\mathrm{Ni}$ has about ten times higher metal value than $\mathrm{Cd}$, which make it the most interesting metal for recycling.

More than $90 \%$ of the produced $\mathrm{NiCd}$ batteries are exported to other countries. It is estimated that $90 \%$ of the industrial and $30 \%$ of portable NiCd batteries are collected and recycled (Mattsson 1999). These figures are rather uncertain since the lifetime of the batteries can be 15-25 years. This leads to a continuous accumulation of $\mathrm{NiCd}$ batteries in the society, which will pose a disposal problem in the future. Therefore, stronger incentives will have to be established on the market for a taking care properly of spent NiCd batteries. Since the use of $\mathrm{Cd}$ is under strong environmental and regulative pressure, strategic environmental actions have to be considered if a closed technosperic flow of $\mathrm{NiCd}$ batteries shall be achieved.

In 1999, the factory received the certificate for its establishment of the environmental management system of ISO 14001. This standard demands continuous improvements in the environmental work of companies. The goals set up for improvements of the production are focusing on decreased water consumption and emissions of $\mathrm{Cd}$ to water, substitution of 
polyvinyl alcohol and reduced losses of active materials in the internal processes. These environmental goals have been chosen e.g. since they are of financial interest, possible to measure and achieve. Since environmental evaluation indices are missing it was not possible to quantify the possible effect in total environmental impact if these goals will be achieved.

The results of the impact assessment should be used to indicate trends for strategic purposes. Stewart et al. (1999) showed with case studies how LCA can be integrated with the work of environmental management systems. Though uncertainties of a LCA include limited supply of data, errors in measurements of data as well as some values are based on estimations. Some of the data from the inventory (e.g. water consumption, different kinds of wastes and chemicals) could not be considered since there are no evaluation indices developed.

The amounts of landfilled waste are only evaluated with the ET and ECO methods, although not all diffierent types of waste are considered. The indices for impact assessment used in this study are continuously being developed as the knowledge of potential environmental impacts of different substances and emissions increase. LCA does not deal with certain local effiects or when small amounts of hazardous substances are used. The potential environmental impact may thus have been reduced even more during the period studied than indicated by the impact assessment.

The reduction of some inventory results to single values is a great simplification and the values have to be compared with other data. The benefit of this evaluation is that a larger perspective is considered and many of the measurable parameters are evaluated. It is then possible do find processes which contribute significantly to environmental impact. The disadvantage with aggregated values is that it is hard to measure a response when actions are taken.

\section{CONCLUSIONS}

During the period 1983-98, the environmental impact of different impact categories (e.g. global warming potential and aquatic ecotoxicity) has been reduced 2- 6 times per manufactured NiCd battery by SAFT, Sweden.

The results of the impact assessment by weighting showed that the environmental impact diffiered in the range -48 to $91 \%$ per year according to the methods of ECO, ET, EDIP and EPS. Variations in inventory data have to be considered so that representative data are chosen when making complete life cycle assessments.

The reduction in environmental impact was mainly due to higher production volume of batteries while the energy consumption and dissipative losses of metals were reduced. The ceased use of (e.g. trichloro-ethylene and chloroflour-carbons) did only have a minor effiect on the total environmental impact since the consumed volumes were relatively small.

Considering the whole life cycle of NiCd batteries, it is crucial to achieve better control of the batteries in use to make it possible for potential materials recovery of spent batteries.

Environmental indices can be used to present and evaluate product manufacturing in a system perspective and direct strategies to decreased environmental impact. 


\section{ACKNOWLEDGMENTS}

I thank Mr. Sven-Erik Mattsson and Dr. Lars Erik Johansson, AB SAFT, Oskarshamn, Sweden for information supplied. Financial support of this project by the Knowledge and Competence foundation is gratefully acknowledged.

\section{REFERENCES}

Atkinson, G. C. (1966) A short history of the Jungner NiFe nickel-cadmium battery, Electrochem. Technol. 4 (7-8), 481-488

Azar, C., Holmberg, J., Lindgren, K. (1996) Socio-Ecological Indicators for Sustainability, Ecological Economics 18 p. 89-112 DOI: https://doi.org/10.1016/0921-8009(96)00028-6

CIT (1998) Compilation of characterisation and weighting indices (Excel sheet) Ekologik, Chalmers industriteknik, Gothenburg

Energiskattegruppen (1999) http://naring.regeringen.se/energi/energiskatter.htm (10.6.1999)

Holmberg, J., Karlsson, S. (1995) On designing socio-ecological indicators in Svedin, , U. and Hägerhäll-Aniansson, B. (eds.) Society and Environment: A Swedish Research Perspective, p. 89- 106, Kluwer Academic Publishers, Dordrecht

ISO (1997) 14040 Environmental Assessment, Life Cycle Assessment- Principles and framework, International Organisation for Standardisation, Brussels

Kertes, A. (1996) Life cycle assessment of three available battery technologies for electric vehicles in a Swedish perspective, MSc thesis, TRITA-IMA ex 1996:7, Dept. Environmental technology and work science, Royal institute of technology, Stockholm, Sweden.

Klostermann, J. E. M., Tukker, A. (1998) Product innovation and Eco-efficiency- Twentythree industry effiorts to reach factor four, Kluwer Academic Publishers, Dordrecht

Kuhre L. W. (1998) ISO 14031 Environmental Performance Evaluation (EPE), Prentice Hall, New Jersey

Mattson, S.-E. (1999) AB SAFT, Oskarshamn, Sweden, pers. com.

Nilsson, J. (1997) Socio-ecological indicators in firms- applied on AB Gothenburg Energy (in Swedish) M. Sc. thesis, Inst. Physical Resource Theory, Chalmers and Gothenburg University, Gothenburg

SAFT (1983-98) Environmental reports (in Swedish), AB SAFT, Oskarshamn

Schmidt-Bleek, F. (1994) Carnoules declaration of the factor ten club, Wuppertal Institute

Stewart, J. R., Collins, M. W., Anderson, R., Murphy, W.R. (1999) Life cycle assessment as a tool for environmental management, Clean products and process, 1, p. $73-81$

DOI: https://doi.org/10.1007/s100980050013

Svensson, A. (1998) Miljörapporter Report 1998:13, Kalmar County Council (in Swedish)

Weizsäcker, E., Lovins, A. B., Lovins, L. H. (1997) Factor four: Doubling wealth, halving resource use, The new report to the Club of Rome, Earthscan Publications Ltd., London 